\title{
Crystal Chemistry, Magnetic and Dielectric Properties of Nickel Doped Strontium Ferrites
}

\author{
Maramu Nyathani 1(D), Gaddameedi Sriramulu 1, Tadiboyina Anil Babu 3(D), Narasipuram \\ VenkataKrishna Prasad $^{3}$ (D), Dachepalli Ravinder 2,*iD), Sadhana Katlakunta ${ }^{1, *}$ (D) \\ 1 Department of Physics, University College of Science, Saifabad, Osmania University, Hyderabad-500004, Telangana, \\ India \\ 2 Department of Physics, Osmania University, Hyderabad-500007, Telangana, India \\ 3 Department of Physics, GITAM Deemed to be University, Bangalore, Karnataka-562163, India \\ * Correspondence: sadhanaphysics@gmail.com (S.K.); ravindergupta28@ rediffmail.com (D.R.);
}

Scopus Author ID 57190787752

Received: 1.03.2021; Revised: 10.04.2021; Accepted: 15.04.2021; Published: 26.04.2021

\begin{abstract}
The $\mathrm{SrNi}_{x} \mathrm{Fe}_{12-2 \mathrm{x}} \mathrm{O}_{19}$ (where $x=0.0-0.8$ ) hexaferrites powders were synthesized using Coprecipitation method and the pellets were prepared at $1100{ }^{\circ} \mathrm{C} / 4 \mathrm{~h}$ in muffle furnace. XRD, FTIR, SEM and EDS analysis were used to analyze the samples structural parameters. The changes in the lattice parameters ' $a$ ' $\&$ ' $c$ ' are due to the differences in ionic radii. The average grain size $(\langle\mathrm{D}\rangle)$ was estimated from SEM images and found to be in between $1.713 \mu \mathrm{m}(x=0)-0.549 \mu \mathrm{m}(x=1.0)$. Observations indicated a decrease in saturation magnetization decreased from $68 \mathrm{emu} / \mathrm{g}(x=0.0)$ to $50 \mathrm{emu} / \mathrm{g}(x=$ $0.6)$ and for $x>0.6, M_{\mathrm{S}}$ increases to $64 \mathrm{emu} / \mathrm{g}(x=0.8)$. The coercivity exhibit anisotropic variation with doping concentration. In the present investigation, the samples shows $\varepsilon=487$; $\tan \delta=1.97$ for $x=$ 0.6 , and $\varepsilon=181 ; \tan \delta=1.01$ for $x=0.8$, respectively. The observed results can be explained on the basis of composition,relaxationphenomena and super exchange interaction.
\end{abstract}

Keywords: M-type hexaferrite; co-precipitation method; crystal structure; dielectric properties.

(C) 2020 by the authors. This article is an open-access article distributed under the terms and conditions of the Creative Commons Attribution (CC BY) license (https://creativecommons.org/licenses/by/4.0/).

\section{Introduction}

Current research focuses on altering dielectric, magnetic, and structural properties of hexaferrite by doping different divalent and trivalent cations at iron sites to get suitable saturation magnetization, coercivity, and dielectric properties for specific high-frequency applications. There are several articles on substituting the $\mathrm{Fe}^{3+}$ ions by magnetic or nonmagnetic $3+$ ions but fewer studies on substitution of $\mathrm{Fe}^{3+}$ ions by magnetic or non-magnetic $2+$ ions in $\mathrm{Ba}-\mathrm{SrFe}_{12} \mathrm{O}_{19}$ hexaferrite. Researchers reported that when trivalent cations such as $\mathrm{Ce}^{3+}[1], \mathrm{Sm}^{3+}$ [2], $\mathrm{Ga}^{3+}$ [3] were substituted for $\mathrm{Fe}^{3+}$ ions increased the coercivity of Barium hexaferrite while substituting $\mathrm{Al}^{3+}[4]$, and $\mathrm{Cr}^{3+}[5]$ at $\mathrm{Fe}^{3+}$ decreased the coercivity. The substitution of $\mathrm{Fe}^{3+}$ ions by divalent metal cations such as $\mathrm{Ca}^{2+}[6], \mathrm{Co}^{2+}[7], \mathrm{Mn}^{2+}[8], \mathrm{Cu}^{2+}$ [9] and $\mathrm{Ni}^{2+}$ [10-11] altered the structural, magnetic and dielectric properties. Monitoring of ferrites indicated that their properties are highly affected due to altered chemical composition, distribution of cations in the crystal lattice, and synthesis method.

Different synthesis methods were reported for the preparation of hexaferrite, such as solid-state method [12-15], co-precipitation [16-19], sol-gel [20-22], and microwave hydrothermal [5], each though each method has its advantages and disadvantages. Therefore, in the present investigation, the $\mathrm{Fe}^{3+}$ ions were substituted by $\mathrm{Ni}^{2+}$ ions in $\mathrm{SrFe}_{12} \mathrm{O}_{19}$. The 
substitution of $\mathrm{Fe}^{3+}$ by $\mathrm{Ni}^{2+}$ in $\mathrm{SrFe}_{12-x} \mathrm{Ni}_{\mathrm{x}} \mathrm{O}_{19}$ will change the structural, magnetic, and dielectric properties because the ionic size and ionic sates are different for $\mathrm{Fe}^{3+}$ and $\mathrm{Ni}^{2+}$ ions. This substitution may create holes or oxygen vacancies in the system, which leads to a decrease in saturation magnetization. Pratap Behera et al. [10] prepared the $\mathrm{BaFe}_{12}{ }_{-} \mathrm{Ni}_{\mathrm{x}} \mathrm{O}_{19}(x=0-0.5)$ hexaferrite by sol-gel method and observed that Ms decreased from $68.16 \mathrm{emu} / \mathrm{g}(x=0)$ to 8.99 $\mathrm{emu} / \mathrm{g}(x=1)$ with increase in $\mathrm{Ni}^{2+}$ ion concentration. Mousavi Ghahfarokhi et al. [11] used the combustion sol-gel method to prepare $\mathrm{SrFe}_{12}{ }_{\mathrm{x}} \mathrm{Ni}_{\mathrm{x}} \mathrm{O}_{19}$ nanoparticles $(x=0-1)$ and found a similar trend in volume and Ms.

The purpose of the present study is to synthesize the uniform distribution of particles using the Co-precipitation method. The $\mathrm{Fe}^{3+}$ ions were replaced by $\mathrm{Ni}^{2+}$ ions and maintained the stoichiometry of $\mathrm{SrFe}_{12-\mathrm{xNi}} \mathrm{Ni}_{19}(0.0 \leq x \geq 1.0)$ hexaferrite. The impact of $\mathrm{Ni}^{2+}$ doping on the dielectric, magnetic, and structural were studied and reported in this paper. Since the ferrites are insulators at room temperature; therefore, their resistivity is high. $\mathrm{Ni}^{2+}$ doping into hexaferrite decreases the loss and dielectric constant, making them suitable for microwave devices and as dielectric filler in electromagnetic attenuation materials [23].

\section{Materials and Methods}

\subsection{Experimental method.}

In the present work, the $\mathrm{SrNi}_{\mathrm{x}} \mathrm{Fe}_{12-\mathrm{x}} \mathrm{O}_{19}(x=0.0-1.0 @ 0.2 \mathrm{wt} \%)$ is synthesized using co-precipitation method. All the precursors used in the synthesis were of analytical grade nitrites. All the salts of ferric nitrate, strontium nitrate, and nickel nitrate were dissolved in deionized water as per the stoichiometry and stirred for 1 hour. A solution of $10 \mathrm{M} \mathrm{NaOH}$ was added to the salt solution, and the $\mathrm{pH}$ was maintained at $\sim 12$, and the stirring was kept sustained. The homogeneity of the mixture was maintained throughout by continuous stirring. The precipitate was filtered and washed several times using deionized water and further with ethanol. Washed precipitates were kept in a hot air oven (Universal itherm A1-7981) at $80{ }^{\circ} \mathrm{C}$ overnight. An average yield of $96 \%$ was obtained.

Polyvinyl alcohol (binder) of 2 wt.\% was mixed with synthesized powders and was pressed uniaxially at $800 \mathrm{~kg} / \mathrm{cm}^{2}$ pressure to form pellets of $1.2 \mathrm{~mm}$ thickness and diameter of $8 \mathrm{~mm}$. Sintering of pellets at $1100{ }^{\circ} \mathrm{C} / 4 \mathrm{~h}$ was done in a muffle furnace in atmospheric air (Navyug India NIC-4000).

\subsection{Structural characterizations.}

The X-ray diffraction patterns were recorded for the sintered samples using an X-ray diffractometer (Phillips PAN analytical) with $\mathrm{Cu}-\mathrm{K}_{\alpha}$ irradiation $(1.5406 \AA$ ) in the scanning range of $2 \theta=20^{\circ}-80^{\circ}$ with a scan rate of $1 \%$ min at $40 \mathrm{kV}$ and $30 \mathrm{~mA}$. The lattice constants $(a \& c)$, X-ray density $\left(d_{\mathrm{x}}\right)$, and volume of the unit cell $(V)$ were calculated using the following equations

$$
\frac{1}{d^{2}}=\left\{\frac{4\left(h^{2}+k h+l^{2}\right)}{3 a^{2}}\right\}+\frac{l^{2}}{c^{2}}
$$

$d_{\mathrm{x}}=2 \mathrm{M} / \mathrm{NV} ;$ and $V=a^{2} c \sin \theta$.

Where $h, k, l$ are miller indices; $a \& c$ are lattice constants in $\AA$; $d$ is the interatomic distance in $\AA$; $M$ is the samples molecular weight, $\mathrm{N}$ is the Avogadro Number. A technique of non-linear fitting between measured and calculated diffraction patterns based on the crystal structure data 
by the least-squares method is known as Rietveld method. Rietveld refinement for all the $\mathrm{Ni}^{2+}$ doped hexaferrite samples was carried out using MAUD software [24]. Fourier Transform Infrared (FTIR) spectrum was recorded on Brucker - Tensor 27 spectrometer in the mid-IR range of $4000-400 \mathrm{~cm}^{-1}$ with a resolution of $4 \mathrm{~cm}^{-1}$. The samples were prepared using $\mathrm{KBr}$ pellet method. A $2 \mathrm{mg}$ of sintered powder was mixed with $300 \mathrm{mg}$ of $\mathrm{KBr}$ powder (spectroscopic grade) and ground thoroughly to get a homogeneous mixture, which was pressed into $13 \mathrm{~mm}$ diameter pellets at 10 tons pressure. The pellets were then heated at $110{ }^{\circ} \mathrm{C}$ for 2 to 3 hours. The microstructural analysis was carried out using a Scanning Electron Microscope (SEM) (Tescan, Vega 3 LMU) coupled with energy-dispersive X-ray spectroscopy (EDS) was used for elemental and morphological information. Image $J$ software was used for the in-depth understanding of sample's microstructure (mean grain size, grain size distribution, histograms), and the effect of Ni doping on the granular structure [25]. Measurements of magnetization versus magnetic field $(\mathrm{M}-\mathrm{H})$ loops using vibrating sample magnetometer (VSM) Lakeshore 7500, USA at normal temperature was used to study the magnetic properties that include coercive field $\left(H_{c}\right)$, saturation magnetization $\left(M_{s}\right)$, and remnant magnetization $\left(M_{r}\right)$. The frequency variation of dielectric constant and loss $(\varepsilon \& \tan \delta)$ were measured using LCR meter (PSM 1705) in the range $10^{2}-10^{6} \mathrm{~Hz}$ at room temperature.

The dielectric constant $(\varepsilon)$ was determined using the relation:

$$
\varepsilon=\mathrm{Cd} / \varepsilon_{0} \mathrm{~A}
$$

where $\mathrm{C}$ the pellet's capacitance in farads, $\mathrm{d}$ is the thickness of the pellet in meters, A the pellets cross-sectional area, and $\varepsilon_{0}$ the permittivity of free space.

$\tan \delta=\mathrm{R}_{\mathrm{s}} / \omega \mathrm{L}_{\mathrm{s}}$, where $\omega, \mathrm{R}_{\mathrm{s}}$ and $\mathrm{L}_{\mathrm{s}}$ are the angular frequency, circuit resistance and circuit inductance. For good electrical contacts for measurements, the sintered pellets were coated with silver paste with approximately $1 \mu \mathrm{m}$ thickness.

\section{Results and Discussion}

\subsection{XRD analysis.}

$\mathrm{XRD}$ is a versatile and non-destructive technique used for phase identification, measurement of crystallite size, and other structural parameters. Fig. 1 (a) displays the XRD patterns of $\mathrm{Ni}^{2+}$ doped $\mathrm{SrFe}_{12} \mathrm{O}_{19}(x=0$ to 1 with intervals 0.20$)$ in which all diffraction peaks were indexed with JCPDS card No's: 33-1340 within space group P63/mmc (no.194) $\left(\mathrm{SrFe}_{12} \mathrm{O}_{19}\right), 33-0664\left(\alpha-\mathrm{Fe}_{2} \mathrm{O}_{3}\right)$ and $73-1523(\mathrm{NiO}), 74-1913\left(\mathrm{NiFe}_{2} \mathrm{O}_{4}\right)$, and it is found that all the peaks were matched well with the hexaferrite phase.

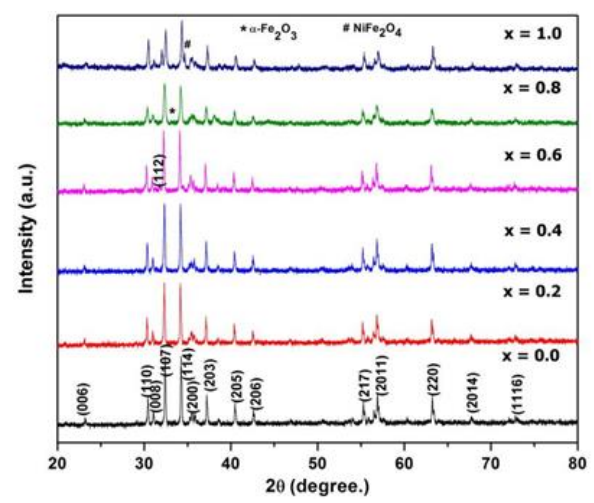

Figure 1. (a) X-ray diffraction patterns of $\mathrm{Ni}^{2+}$ substituted $\mathrm{SrFe}_{12} \mathrm{O}_{19}(0.0 \leq \mathrm{x} \geq 1.0)$ hexaferrites. 
The miller indices $\left(\begin{array}{lll}1 & 0 & 7\end{array}\right)$ and $\left(\begin{array}{lll}1 & 1 & 4\end{array}\right)$ are the characteristic peaks of $\mathrm{SrFe}_{12} \mathrm{O}_{19}$. No impurity phases were observed for $x=0.0$ up to 0.4 concentration. At higher concentrations ( $x$ $\geq 0.6$ ) of $\mathrm{Ni}^{2+}$ ions doping, the secondary phases such as $\alpha-\mathrm{Fe}_{2} \mathrm{O}_{3}$ and $\mathrm{NiFe}_{2} \mathrm{O}_{3}$ were observed. $\mathrm{The}_{\mathrm{NiFe}} \mathrm{O}_{3}$ phase is dominant at higher $(x=1.0)$ dopant concentrations [11] due to smaller strontium hexaferrite units similar to $\mathrm{S}$-shaped cubic block having spinel-like structure and $\mathrm{R}$ shaped hexagonal block containing $\mathrm{Sr}$ ions. The additional $\alpha-\mathrm{Fe}_{2} \mathrm{O}_{3}$ phase $\left(2 \theta=33.10^{\circ}\right)$ is observed, and it is more prominent at higher concentrations of $\mathrm{Ni}^{2+}$ doping. The charge neutrality in hexaferrite occurs when one cation replaces another cation compensating Fe ions $\left(\mathrm{Fe}^{2+} \leftrightarrow \mathrm{Fe}^{3+}\right)[26]$ among them. When $\mathrm{Fe}^{3}+$ ions are replaced by $\mathrm{Ni}^{2+}$ ions at $\mathrm{B}$ sites probability of $\mathrm{Fe}^{2+}$ reacting with oxygen to form a- $\mathrm{Fe}_{2} \mathrm{O}_{3}$ phase is high, which is evident from XRD (Fig.1a). There is no effect of the hematite phase on the magnetic properties of current samples since it is non-magnetic.

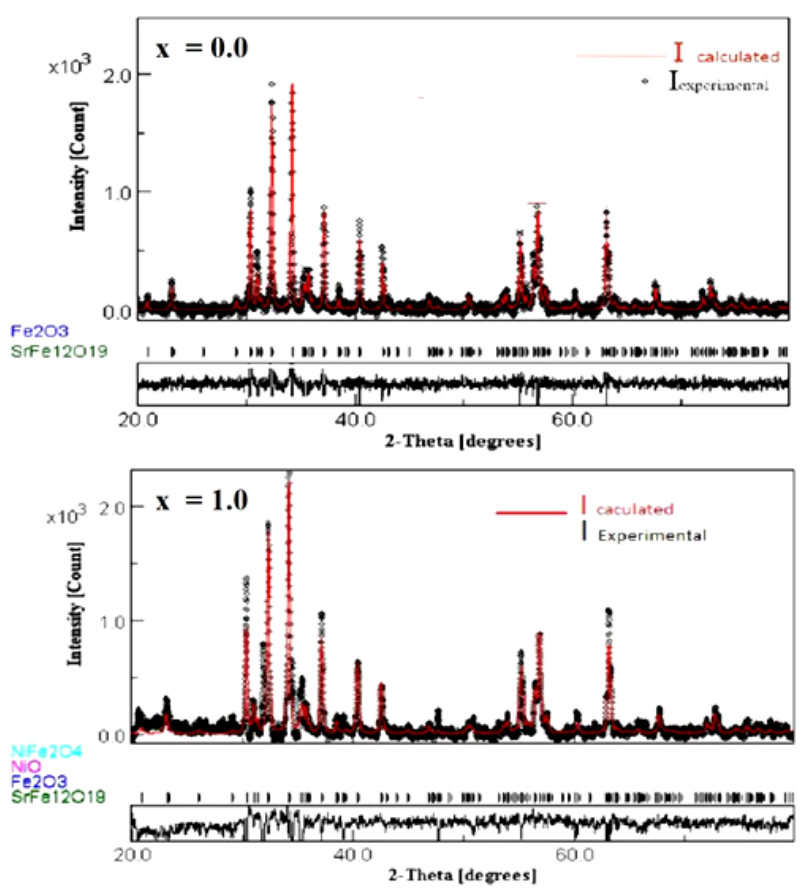

Figure 1. (b) Rietveld refinement of $\mathrm{Ni}^{2+}$ substituted $\mathrm{SrFe}_{12} \mathrm{O}_{19}(\mathrm{x}=0.0$ \& 1.0) hexaferrites.

Figure 1(b) shows the Rietveld refinements for sample $\mathrm{x}=0.0$ and 1.0. Rietveld refinements of XRD patterns for all samples were carried out using MAUD software using $\mathrm{P}_{3} / \mathrm{mmc}$ space group and $\mathrm{R} 3 \mathrm{c}$ used for the second phase, which indicated a good correlation between calculated and experimental data. The lattice parameter $(a \& c), R_{p}$ (profile fitting Rvalue), $R_{w p}$ (Weighted profile R-Value), $R_{\text {Bragg }}$ (Bragg value), $R_{\exp }$ (expected value),Sig (goodness of fit (GOF) quality factor), X-ray density $\left(d_{x}\right)$, and unit cell volume (V) were tabulated in Table 1 . The least values of $R_{p}, R_{w p}$, and $\operatorname{Sig}(\mathrm{GOF})$ indicate good quality samples and effective refinement. The increase in lattice constants with the addition of $\mathrm{Ni}^{+2}(0.69 \AA)$ is because of $\mathrm{Ni}^{+2}$ ionic radius being greater than that of $\mathrm{Fe}^{+3}(0.645 \AA)$ ions [10]. Our results are comparable with Pratap Behera et al. [10], where they reported an increase in the lattice parameters with $\mathrm{Ni}^{+2}$ doping in Barium hexaferrite synthesized using sol-gel method and sintered at $1150{ }^{\circ} \mathrm{C} / 12 \mathrm{~h}$. Mousavi Ghahfarokhi et al. [11] prepared $\mathrm{SrFe}_{12}{ }_{x} \mathrm{Ni}_{x} \mathrm{O}_{19}$ nanoparticles $(x=0.0-1.0)$ by a combustion Sol-gel method. The changes in unit cell volume (V) with $\mathrm{Ni}^{+2}$ doping is due to the incorporation of $\mathrm{Ni}^{2+}$ ions into the unit cell of $\mathrm{SrFe}_{12} \mathrm{O}_{19}$ confirms that $\mathrm{Fe}^{2+/ 3+}$ ions are replaced by $\mathrm{Ni}^{2+}$ ions. The c/a ratio is less than 3.98 , which shows 
that the present samples belong to a hexagonal structure [27]. The changes in X-ray density with $\mathrm{Ni}^{2+}$ doping are due to the changes in the molar mass of the sample [28].

Table 1. The lattice parameters $a$ and $c$, unit cell volume $(V)$, X-ray density $\left(d_{x}\right)$, and Rietveld refinement

\begin{tabular}{l|l|l|l|l|l|l}
\multicolumn{7}{c}{ parameters of $\mathrm{SrFe}_{12-\mathrm{x}} \mathrm{Ni}_{\mathrm{x}} \mathrm{O}_{19}$ samples. } \\
Parameters & $\boldsymbol{x}=\mathbf{0 . 0}$ & $\boldsymbol{x}=\mathbf{0 . 2}$ & $\boldsymbol{x}=\mathbf{0 . 4}$ & $\boldsymbol{x}=\mathbf{0 . 6}$ & $\boldsymbol{x}=\mathbf{0 . 8}$ & $\boldsymbol{x}=\mathbf{1 . 0}$ \\
\hline$R_{p}(\%)$ & 1.38 & 1.65 & 2.45 & 2.22 & 2.02 & 2.21 \\
\hline$R_{w p}(\%)$ & 1.54 & 1.45 & 3.05 & 1.68 & 2.52 & 2.73 \\
\hline$R_{\text {Brag }}(\%)$ & 1.35 & 1.34 & 1.86 & 1.55 & 2.03 & 2.45 \\
\hline$R_{\exp }(\%)$ & 10.22 & 11.20 & 10.54 & 10.74 & 11.51 & 11.56 \\
\hline $\mathrm{Sig}(\mathrm{GOF})$ & 1.38 & 1.37 & 2.90 & 1.54 & 2.19 & 2.35 \\
\hline$a(\AA)$ & 5.879 & 5.881 & 5.880 & 5.884 & 5.886 & 5.883 \\
\hline$c(\AA)$ & 23.0468 & 23.0478 & 23.0620 & 23.0627 & 23.0695 & 23.0510 \\
\hline$c / a$ & 3.920 & 3.919 & 3.922 & 3.919 & 3.919 & 3.918 \\
\hline$V\left(\AA^{3}\right)$ & 689.82 & 690.32 & 690.51 & 691.47 & 692.14 & 690.88 \\
\hline$d_{x}\left(\mathrm{~g} / \mathrm{cm}^{3}\right)$ & 5.100 & 5.109 & 5.116 & 5.107 & 5.094 & 5.103 \\
\hline $\begin{array}{l}\mathrm{Avg} \text { grain size } \\
(\mu \mathrm{m}) \text { from SEM }\end{array}$ & 1.713 & 1.470 & 0.902 & 0.776 & 1.274 & 0.549
\end{tabular}

\subsection{SEM and EDS analysis.}

Fig.2 shows the SEM micrographs, histograms of grain size of $\mathrm{SrNi}_{\mathrm{x}} \mathrm{Fe}_{12-\mathrm{x}} \mathrm{O}_{19}(x=0.0$ -1.0), and energy dispersive spectrum (EDS).

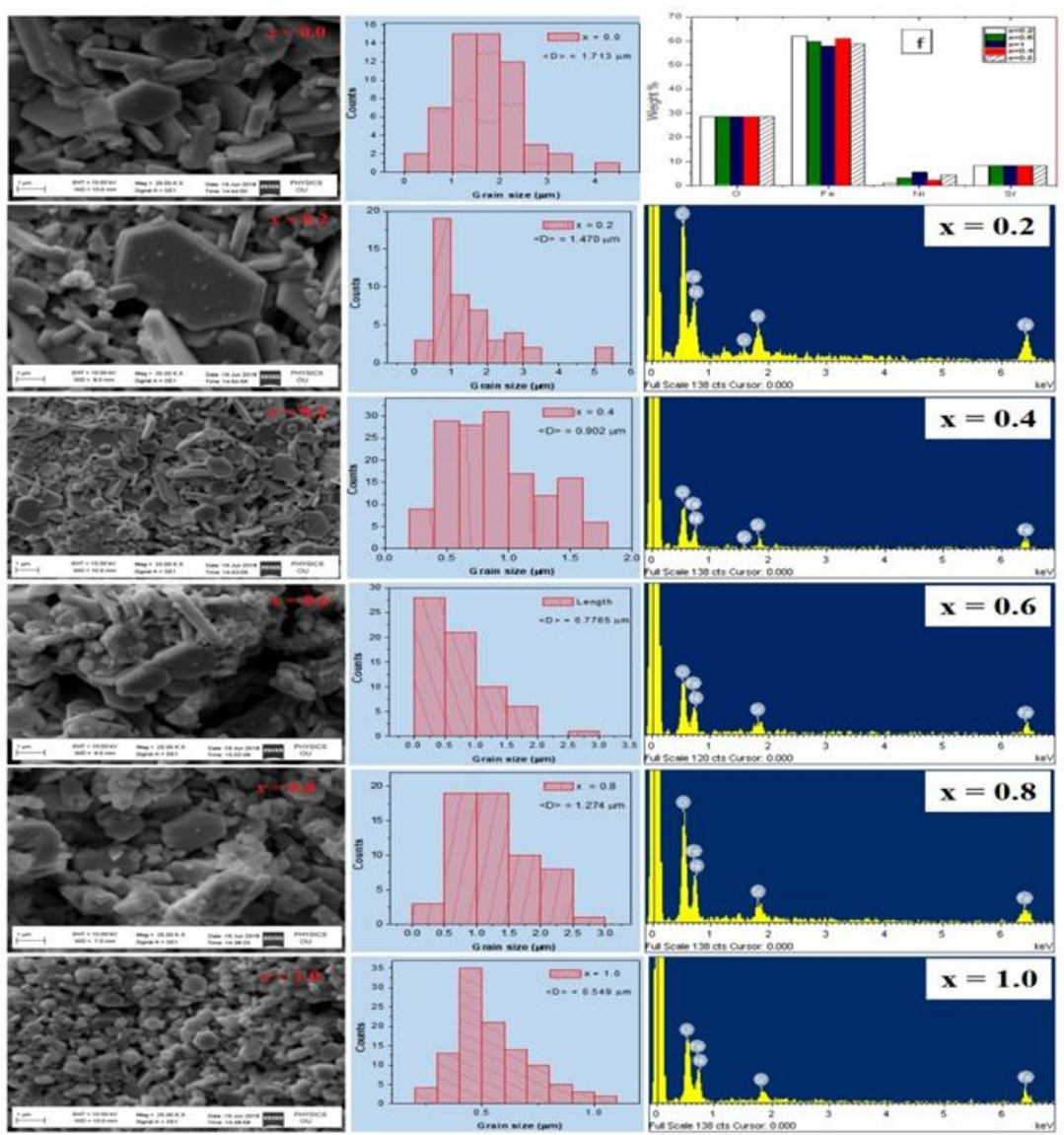

Figure 2. SEM images $(0.0 \leq \mathrm{x} \leq 1)$, histogram of grain size $(0.0 \leq \mathrm{x} \leq 1)$ and $\mathrm{EDS}$ of $\mathrm{Ni}^{2+}$ doped $\mathrm{SrFe}_{12} \mathrm{O}_{19}(0.2$ $\leq \mathrm{x} \leq 1)$ hexaferrites.(f) represents the histogram for wt\% percentage of the elements with varying composition.

It clearly shows that the grains have a hexagonal shape (plate-like structure for $x$ ). The values of average grain sizes are listed in Table 1 and found between $1.713(x=0)-0.49 \mu \mathrm{m}$ $(x=1.0)$. The hexagonal shape is clearly seen for $x=0.0$ to 0.6 and $x>0.2$, the particles are agglomerated. Along with a hexagonal plate-like structure, a small amount of $\alpha-\mathrm{Fe}_{2} \mathrm{O}_{3}$ and 
$\mathrm{NiFe}_{2} \mathrm{O}_{4}$ (seen in XRD, Fig. 1a) can be seen. With $\mathrm{Ni}^{2+}$ doping, the agglomeration of grains increased. The variation in grain size was due to the agglomeration of the particle collections, which resulted in inhomogeneous size distribution.

Energy Dispersive X-ray Spectroscopy (EDS) is a technique of analyzing an element that can give information related to the chemical composition of a sample. It is a qualitative as well as a quantitative technique. Confirmation of chemical composition of $\mathrm{SrNi}_{x} \mathrm{Fe}_{12-x} \mathrm{O}_{19}$ ( $x=$ $0.2-1.0$ in steps of $0.2 \mathrm{wt} \%$ ) can be done through the quantitative elemental analysis by using EDS spectrometer attached to the SEM for all samples. Table 2 shows the estimated and obtained EDS results for doped samples indicating atomic percentage (wt \%) of $\mathrm{Ni}, \mathrm{Sr}, \mathrm{O}$, and Fe, which correlate with designed composition, and these elements are found to be evenly distributed throughout the entire area, which reveals uniform chemical phase.

Table 2. EDS data for Ni substituted $\mathrm{SrFe}_{12} \mathrm{O}_{19}$ hexaferrites.

\begin{tabular}{l|c|c|c|c|c|c|c|c}
\multirow{2}{*}{ Sample } & \multicolumn{4}{|c|}{ Estimated wt \% of elements } & \multicolumn{3}{c}{ Obtained wt \% of elements from EDS } \\
\cline { 2 - 9 } & $\mathrm{Sr}$ & $\mathrm{Fe}$ & $\mathrm{Ni}$ & $\mathrm{O}$ & $\mathrm{Sr}$ & $\mathrm{Fe}$ & $\mathrm{Ni}$ & $\mathrm{O}$ \\
\hline$x=0.2$ & 8.248 & 62.032 & 1.105 & 28.615 & 8.248 & 61.890 & 1.100 & 28.760 \\
\hline$x=0.4$ & 8.243 & 60.948 & 2.209 & 28.599 & 8.243 & 60.775 & 2.205 & 28.59 \\
\hline$x=0.6$ & 8.239 & 59.867 & 3.310 & 28.584 & 8.239 & 59.980 & 3.298 & 28.49 \\
\hline$x=0.8$ & 8.235 & 58.784 & 4.413 & 28.568 & 8.235 & 58.792 & 4.360 & 28.46 \\
\hline$x=1.0$ & 8.230 & 57.703 & 5.513 & 28.554 & 8.230 & 57.810 & 5.454 & 28.5
\end{tabular}

\subsection{FTIR analysis.}

Figure 3, depicts FTIR spectra for $\mathrm{Ni}^{2+}$ doped $\mathrm{SrFe}_{12} \mathrm{O}_{19}(0.0 \leq x \leq 0.8)$ measured in the range $400-4000 \mathrm{~cm}^{-1}$. The absorption bands are seen between $590 \mathrm{~cm}^{-1}-610 \mathrm{~cm}^{-1}$ and $400 \mathrm{~cm}^{-}$ $1-450 \mathrm{~cm}^{-1}$ were due to tetrahedral and octahedral bands of hexaferrite.

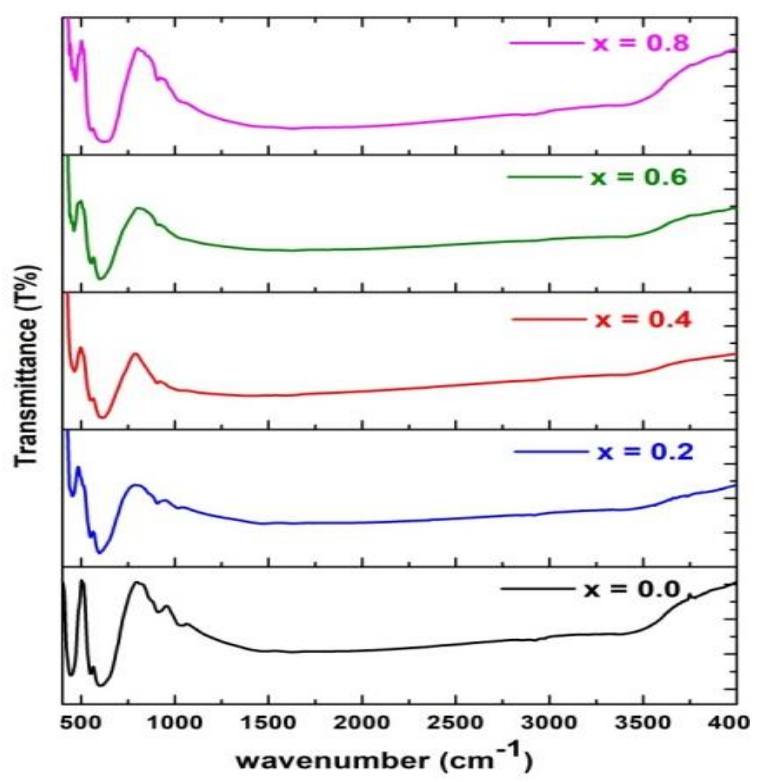

Figure 3 FTIR spectrum for $\mathrm{Ni}^{2+}$ doped $\mathrm{SrFe}_{12} \mathrm{O}_{19}(0.0 \leq \mathrm{x} \leq 0.8)$ hexaferrites.

The changes in the tetrahedral and octahedral bands are due to the changes that occurred in the $\mathrm{Fe}^{3+}-\mathrm{O}^{2}$ - bands because of $\mathrm{Ni}^{2+}$ doping [29]. The bands of metal-oxygen stretching vibrations are observed around $550 \mathrm{~cm}^{-1}$ and $590 \mathrm{~cm}^{-1}$ show the formation of hexagonal structure [30]. The peak shift to the higher wavenumber side is due to the distance between $\mathrm{Fe}^{3+}$ and $\mathrm{O}^{2-}$ ions with increasing doping concentration. The stretching and bending vibration band of Sr-O and Fe-O observed around $910 \mathrm{~cm}^{-1}$ and $1020 \mathrm{~cm}^{-1}$, respectively [31]. The band intensity decreased with $\mathrm{Ni}^{2+}$ doping concentration are due to ionic replacement and changes 
in the magnetic dipole moment. Fig. 3 also shows two bands at $1388 \mathrm{~cm}^{-1}$ and at $3400 \mathrm{~cm}^{-1}$ corresponds to $\mathrm{NO}^{3-}$ stretching vibration and $\mathrm{O}-\mathrm{H}$ group, respectively.

\subsection{Magnetic studies.}

Fig. 4(a) shows the hysteresis loops of $\mathrm{Ni}^{2+}$ doped $\mathrm{SrFe}_{12} \mathrm{O}_{19}(0.0 \leq x \geq 0.8)$ at room temperature, indicating that the samples are magnetically ordered. The saturation magnetization $(M \mathrm{~s})$, remanence $\left(M_{\mathrm{r}}\right)$, the ratio of $M_{\mathrm{r}} / M_{\mathrm{s}}$, and coercivity $\left(H_{\mathrm{C}}\right)$ were tabulated in Table 3. It is clear from Fig. 4(b) that saturation and remnant magnetization decreased with $x$ up to 0.6 and then increased with further doping of $\mathrm{Ni}^{2+}$. The value of $M_{\mathrm{s}}$ decreases from 68 to $50 \mathrm{emu} / \mathrm{g}(x=0.0$ to $x=0.6)$ and for $x>0.6, M_{\mathrm{s}}$ is increased to $64 \mathrm{emu} / \mathrm{g}(x=0.8)$. In hexaferrite, one tetrahedral $\left(4 \mathrm{f}_{1}\right)$, three octahedral $\left(2 \mathrm{a}, 12 \mathrm{k}\right.$, and $\left.4 \mathrm{f}_{2}\right)$, and one trigonalbipyramidal $(2 \mathrm{~b})$ sites are present. Three sites ( $2 \mathrm{a}, 12 \mathrm{k}$ and $2 \mathrm{~b}$ ) are of parallel (spin up, $\uparrow$ ) while two sites $\left(4 \mathrm{f}_{1}\right.$ and $\left.4 \mathrm{f}_{2}\right)$ are of antiparallel spins (spin down, $\downarrow$ ) [9]. The ferromagnetic structure is formed by a superexchange interaction between the iron atoms in the structural sites through $\mathrm{O}^{2-}$ ions [32]. The increase of $\mathrm{Ni}^{2+}$ cations replaces $\mathrm{Fe}^{3+}$ ions, $(x=0$ to 0.6$)$, the saturation magnetization $\left(M_{\mathrm{s}}\right)$ decreased as the magnetic moment per unit volume decreased. For $x>0.6, M_{\mathrm{s}}$ is increased because, at higher concentrations of $x$, a very small amount of $\mathrm{NiFe}_{2} \mathrm{O}_{3}$ as a secondary phase is formed (seen in XRD, Fig.1). The substitution of higher concentration of $\mathrm{Ni}^{2+}$ ions increase the superexchange interaction between $\mathrm{Fe}^{3+}$ ions at spin up sites and therefore the $M_{\mathrm{s}}$ increased from $50 \mathrm{emu} / \mathrm{g}(x=0.6)$ to $64 \mathrm{emu} / \mathrm{g}(x=0.8)$.
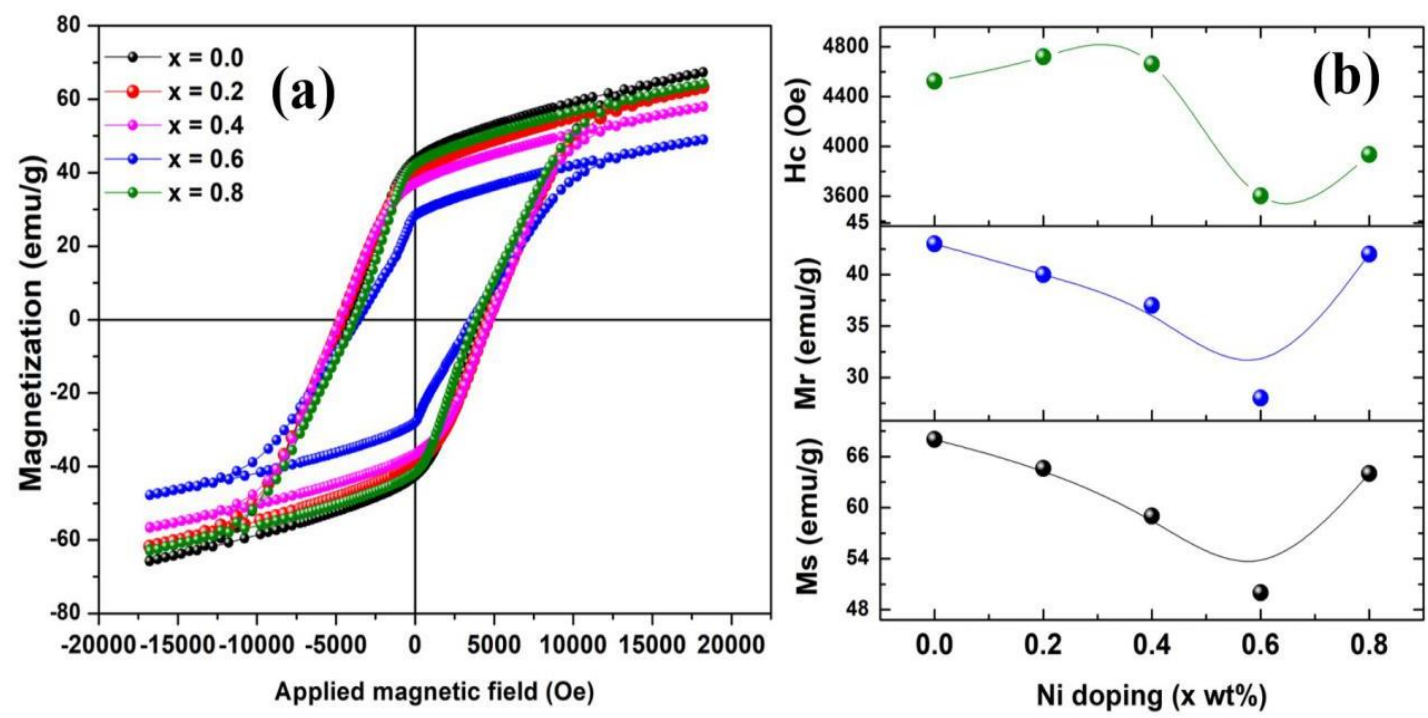

Figure 4. (a) Room temperature magnetic hysteresis loops of $\operatorname{SrNi}_{\mathrm{x}} \mathrm{Fe}_{12-\mathrm{x}} \mathrm{O}_{19}(0.0 \leq x \geq 0.8)$ (b) Dependence of Magnetic data $\left(\mathrm{M}_{\mathrm{s}}, \mathrm{M}_{\mathrm{r}}\right.$, and $\left.\mathrm{H}_{\mathrm{c}}\right)$ with $\mathrm{Ni}^{2+}$ substitution.

The range of squareness ratio $\left(M_{\mathrm{r}} / M_{\mathrm{s}}\right)$ between $0.560-0.656$ confirms the single domain of prepared samples [33-36]. The coercivity $\left(H_{\mathrm{C}}\right)$ increased anisotropically with doping. The value of $H_{\mathrm{C}}$ increased for $x=0.2$ and then decreased upto $x=0.6$ and for $x=0.8, H_{\mathrm{C}}$ increased again. The substitution of ions at octahedral $(12 \mathrm{k}, 4 \mathrm{f} 2)$ and trigonal bi-pyramidal $(2 \mathrm{~b})$ sites contributes to magnetocrystalline anisotropy in hexaferrite. The decrease in coercivity for $\mathrm{x}=$ 0.2 to 0.6 may be related to the magnetocrystalline anisotropy field [9]. The increase in $H_{\mathrm{C}}$ for $x=0.8$ is due to the formation of impurity phases, which is evident from XRD (Fig.1a) and SEM (Fig. 2), respectively. 
Table 3. Room temperature data of $\mathrm{M}_{\mathrm{s}}, \mathrm{M}_{\mathrm{r}}, \mathrm{H}_{\mathrm{c}}, \varepsilon$ and $\tan \delta$ (at $100 \mathrm{~Hz}$ ) for $\mathrm{Ni}^{2+}$ doped strontium hexaferrite.

\begin{tabular}{c|c|c|c|c|c|c}
$\boldsymbol{x}$ & $\begin{array}{c}\mathbf{M}_{\mathbf{s}} \\
(\mathbf{e m u} / \mathbf{g})\end{array}$ & $\begin{array}{c}\mathbf{M}_{\mathbf{r}} \\
(\mathbf{e m u} / \mathbf{g})\end{array}$ & $\mathbf{M}_{\mathbf{r}} / \mathbf{M}_{\mathbf{s}}$ & $\begin{array}{c}\mathbf{H}_{\mathbf{c}} \\
(\mathbf{O e})\end{array}$ & $\boldsymbol{\varepsilon}$ & $\tan \boldsymbol{\delta}$ \\
\hline 0.0 & 68 & 43 & 0.632 & 4525 & 14531 & 6.13 \\
\hline 0.2 & 65 & 40 & 0.615 & 4720 & 10338 & 4.77 \\
\hline 0.4 & 59 & 37 & 0.627 & 4662 & 4489 & 4.50 \\
\hline 0.6 & 50 & 28 & 0.560 & 3602 & 487 & 1.97 \\
\hline 0.8 & 64 & 42 & 0.656 & 3936 & 181 & 1.01
\end{tabular}

\subsection{Dielectric studies.}

Fig. 5(a \& b) shows the frequency variation of dielectric constant $(\varepsilon)$ and $\tan \delta$ for $\mathrm{SrNi}_{x} \mathrm{Fe}_{12-x} \mathrm{O}_{19}(x=0.0-0.8)$ at room temperature measured between $10^{2}$ to $10^{6} \mathrm{~Hz}$.
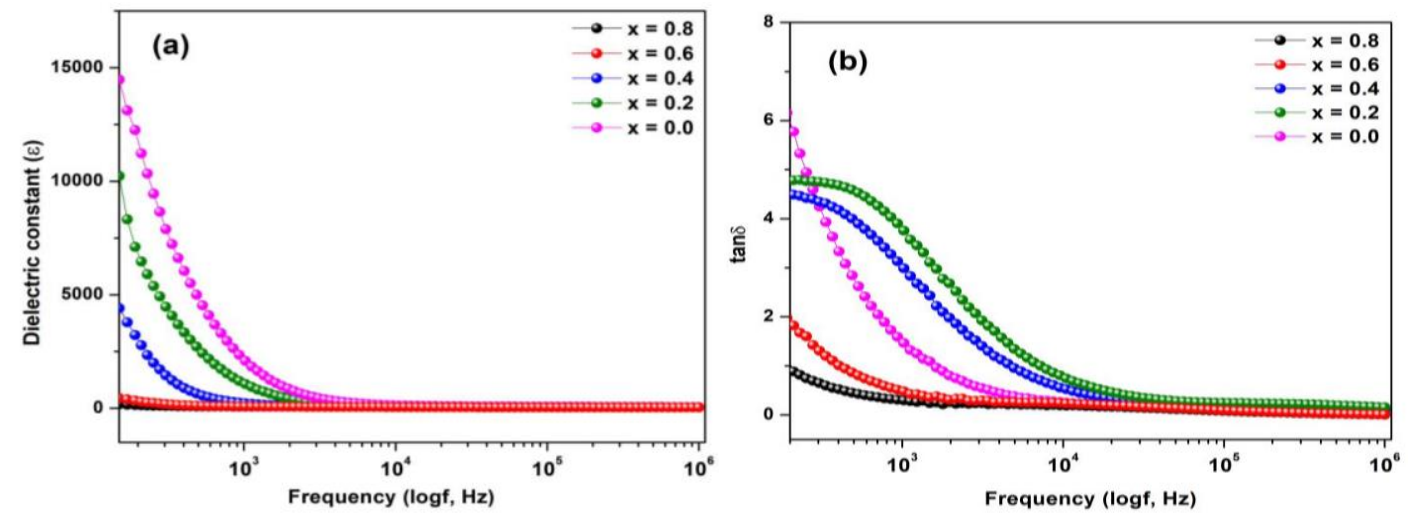

Figure 5. (a) Dielectric constant $\left(\varepsilon^{\prime}\right)$ and (b) $\tan \delta$ as a function of $\log f(\mathrm{~Hz})$ for $\mathrm{SrNi}_{x} \mathrm{Fe}_{12-x} \mathrm{O}_{19}$ hexaferrite at room temperature.

Figure 5a indicates a high value of $\varepsilon$ at $100 \mathrm{~Hz}$ and a low value above $1 \mathrm{kHz}$ due to the relaxation process accompanied by a relaxation peak observed in Fig. $5 b(x=0.4 \& 0.6)$. Space charge polarization decreases $\varepsilon$ value with frequency increase. The decrease in $\varepsilon$ at a higher frequency is due to the lag in the change in orientation of the dipoles due to the inertial and spatially oriented defects [37]. The values of dielectric constant $(\varepsilon)$ and $\tan \delta$ at $100 \mathrm{~Hz}$ are given in Table 3. It is observed that $\varepsilon$ and $\tan \delta$ decreased with $\mathrm{Ni}^{2+}$ doping. Iwauchi [38] reported that in ferrites, the conduction mechanism and polarization are similar. It is reported that the hopping of electrons between $\mathrm{Fe}^{2+} / \mathrm{Fe}^{3+}$ at octahedral sites takes place in the conduction mechanism, whereas dielectric polarization might be due to conduction between positive holes and electrons that arise due to oxygen loss during sintering and/or substitution of metal ions [28]. The doping of $\mathrm{Ni}^{2+}$ ions into hexaferrite decreased dielectric constant and loss. In the present investigation, the samples shows $\varepsilon=487$; $\tan \delta=1.97$ for $x=0.6$, and $\varepsilon=181 ; \tan \delta=$ 1.01 for $x=0.8$, respectively. The penetration depth of electromagnetic waves can be decreased by the materials possess a high dielectric constant. Therefore, the materials with lower dielectric constant and loss can be useful at high frequency [39-41].

\section{Conclusions}

The $\mathrm{SrNi}_{\mathrm{x}} \mathrm{Fe}_{12-\mathrm{x}} \mathrm{O}_{19}(0.0 \leq x \geq 1.0)$ hexaferrites were synthesized using Co-precipitation method and densified at $1100{ }^{\circ} \mathrm{C} / 4 \mathrm{~h}$ using conventional sintering method. No impurity phases were observed for $x=0.0$ upto 0.4 concentration but for $x \geq 0.6$, secondary phases were observed. The changes in lattice parameters were due to the difference in the ionic radii. The values of average grain sizes are found between $1.713(x=0)-0.49 \mu \mathrm{m}(x=1.0)$. The $M \mathrm{~s}$ decreased with $x$ upto 0.6 and for $x>0.6, M_{\mathrm{S}}$ increased. The decrease in coercivity for $\mathrm{x}=0.2$ 
to 0.6 is may be related to the magnetocrystalline anisotropy field. The squareness ratio $\left(M_{\mathrm{r}} / M_{\mathrm{s}}\right)$ range between $0.560-0.656$ confirming single domain of prepared samples. It is observed that $\varepsilon$ and $\tan \delta$ decreased with $\mathrm{Ni}^{2+}$ doping. In the present investigation, the samples shows $\varepsilon=487$; $\tan \delta=1.97$ for $x=0.6$, and $\varepsilon=181$; $\tan \delta=1.01$ for $x=0.8$, respectively.

\section{Funding}

This research received no external funding.

\section{Acknowledgments}

Maramu Nyathani conveys his sincere thanks to Prof. D. Ravinder \& Sadhana K for their enthusiastic encouragement and guidance to pursue Ph.d. The authors are also grateful to the Head Department of Physics, University College of Science, Osmania University, Hyderabad.

\section{Conflicts of Interest}

The authors declare no conflict of interest.

\section{References}

1. Pawar, R.A.; Desai, S.S.; Tamboli, Q.Y.; Shirsath, S.E.; Patange, S.M. Ce3+ incorporated structural and magnetic properties of $\mathrm{M}$ type barium hexaferrites. Journal of Magnetism and Magnetic Materials 2015, 378, 59-63, https://doi.org/10.1016/j.jmmm.2014.10.166.

2. Wang, L.; Zhang, J.; Zhang, Q.; Xu, N.; Song, J. XAFS and XPS studies on site occupation of Sm3+ ions in Sm doped M-type BaFe12O19. Journal of Magnetism and Magnetic Materials 2015, 377, 362-367, https://doi.org/10.1016/j.jmmm.2014.10.097.

3. Bsoul, I.; Mahmood, S.H. Magnetic and structural properties of BaFe12-xGaxO19 nanoparticles. Journal of Alloys and Compounds 2010, 489, 110-114, https://doi.org/10.1016/j.jallcom.2009.09.024.

4. Dhage, V.N.; Mane, M.L.; Keche, A.P.; Birajdar, C.T.; Jadhav, K.M. Structural and magnetic behaviour of aluminium doped barium hexaferrite nanoparticles synthesized by solution combustion technique. Physica B: Condensed Matter 2011, 406, 789-793, https://doi.org/10.1016/j.physb.2010.11.094.

5. Katlakunta, S.; Meena, S.S.; Srinath, S.; Bououdina, M.; Sandhya, R.; Praveena, K. Improved magnetic properties of $\mathrm{Cr} 3+$ doped $\mathrm{SrFe} 12 \mathrm{O} 19$ synthesized via microwave hydrothermal route. Materials Research Bulletin 2015, 63, 58-66, https://doi.org/10.1016/j.materresbull.2014.11.043.

6. Moon, K.-S.; Lim, E.-S.; Kang, Y.-M. Effect of Ca and La substitution on the structure and magnetic properties of M-type Sr-hexaferrites. Journal of Alloys and Compounds 2019, 771, 350-355, https://doi.org/10.1016/j.jallcom.2018.08.306.

7. Chavan, V.C.; Shirsath, S.E.; Mane, M.L.; Kadam, R.H.; More, S.S. Transformation of hexagonal to mixed spinel crystal structure and magnetic properties of $\mathrm{Co} 2+$ substituted BaFe12O19. Journal of Magnetism and Magnetic Materials 2016, 398, 32-37, https://doi.org/10.1016/j.jmmm.2015.09.002.

8. Sharma, P.; Rocha, R.A.; Medeiros, S.N.; Hallouche, B.; Paesano, A. Structural and magnetic studies on mechanosynthesized BaFe12-xMnxO19. Journal of Magnetism and Magnetic Materials 2007, 316, 29-33, https://doi.org/10.1016/j.jmmm.2007.03.207.

9. Rafiq, M.A.; Waqar, M.; Muhammad, Q.K.; Waleed, M.; Saleem, M.; Anwar, M.S. Conduction mechanism and magnetic behavior of $\mathrm{Cu}$ doped barium hexaferrite ceramics. Journal of Materials Science: Materials in Electronics 2018, 29, 5134-5142, https://doi.org/10.1007/s10854-017-8477-y.

10. Behera, P.; Ravi, S. Effect of Ni doping on structural, magnetic and dielectric properties of M-type barium

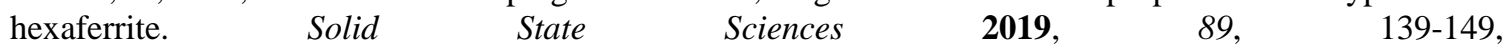
https://doi.org/10.1016/j.solidstatesciences.2019.01.003.

11. Mousavi Ghahfarokhi, S.E.; Hosseini, S.; Zargar Shoushtari, M. Fabrication of SrFe12-xNixO19 nanoparticles and investigation on their structural, magnetic and dielectric properties. International Journal of Minerals, Metallurgy, and Materials 2015, 22, 876-883, https://doi.org/10.1007/s12613-015-1145-4.

12. Singh, J.; Singh, C.; Kaur, D.; Zaki, H.; Abdel-Latif, I.A.; Narang, S.B.; Jotania, R.; Mishra, S.R.; Joshi, R.; Dhruv, P.; Ghimire, M.; Shirsath, S.E.; Meena, S.S. Elucidation of phase evolution, microstructural, Mössbauer and magnetic properties of $\mathrm{Co} 2+\mathrm{Al} 3+$ doped M-type $\mathrm{BaSr}$ hexaferrites synthesized by a ceramic method. Journal of Alloys and Compounds 2017, 695, 1112-1121, http://dx.doi.org/10.1016/j.jallcom.2016.10.237. 
13. Huang, K.; Yu, J.; Zhang, L.; Xu, J.; Li, P.; Yang, Z.; Liu, C.; Wang, W.; Kan, X. Synthesis and characterizations of magnesium and titanium doped M-type barium calcium hexaferrites by a solid state reaction method. Journal of Alloys and Compounds 2020, 825, 154072, https://doi.org/10.1016/j.jallcom.2020.154072

14. Karahroudi, Z.H.; Kambiz, H.; Goodarzi, M. Green synthesis and characterization of hexaferrite strontiumperovskite strontium photocatalyst nanocomposites. Main Group Metal Chemistry, 2020, 43, 26-42, https://doi.org/10.1515/mgmc-2020-0004.

15. Luthfianti, H.R.; Widanarto, W.; Ghoshal, S.K.; Effendi, M.; Cahyanto, W.T.; Magnetic and microwave absorption properties of Mn4+ doped barium-natural ferrites prepared by the modified solid-state reaction method, Journal of Physics: Conference Series, 2020, 1494, 012043, https://doi.org/10.1088/17426596/1494/1/012043

16. Ajeesha, T.L.; Anantharaman, A.; Baby, J.N.; George, M. Structural, Magnetic, Electrical and Photo-Fenton Properties of Copper Substituted Strontium M-Hexagonal Ferrite Nanomaterials via Chemical Coprecipitation Approach. Journal of Nanoscience and Nanotechnology 2020, 20, 1589-1604, https://doi.org/10.1166/jnn.2020.17132.

17. Susilawati, Doyan, A.; Taufik, M.; Wahyudi. The structure of barium M-hexaferrite $\left(\mathrm{BaFe}_{12-2 x} \mathrm{Co}_{\mathrm{x}} \mathrm{Ni}_{\mathrm{x}} \mathrm{O}_{19}\right)$ powders using co-precipitation methods, AIP conference proceedings, 2020, 2251, 040028, https://doi.org/10.1063/5.0015750

18. Tran, N.; Lee, M.Y.; Lee, B.W. Microwave absorption properties of cobalt-doped $\mathrm{BaFe}_{12} \mathrm{O}_{19}$ hexaferrites. Journal of Korean Physical Society, 2020, 77, 1125-1134, https://doi.org/10.3938/jkps.77.1125

19. Sagayaraj, R.; Dhineshkumar, T.; Prakash, A.; Aravazhi, S.; Chandrasekaran, G.; Jayarajan, D.; Sebastian, S.; Fabrication, microstructure, morphological and magnetic properties of W-type ferrite by co-precipitation method: Antibacterial activity, Chemical Physics Letters, 2020, 759, 137944. https://doi.org/10.1016/j.cplett.2020.137944

20. Wong, Y.C.; Wang, J.; Teh, G.B. Structural and Magnetic Studies of SrFe12O19 by Sol-gel Method. Procedia Engineering 2014, 76, 45-52, https://doi.org/10.1016/j.proeng.2013.09.246.

21. Al-Hwaitat E.S.; Dmour, M.K.; Bsoul, I.; Al-Buqain, R.; Mahmood, S.H.; A comparative study of BaxSr1-xFe12O19 ferrite permanent magnets prepared by ball milling and sol-gel routes, Journal of Physics D: Applied Physics, 2020, 53, 364001, https://doi.org/10.1088/1361-6463/ab9135

22. Bankar, S.B.; Meshram, N.S.; Nandanwar, A.K.; Ahamad, H.S.; Dhoble S.J.; Rewatkar K.G. Synthesis and Characterization of Nanocrystalline $\mathrm{Ca}_{2} \mathrm{Cu}_{2} \mathrm{Fe}_{(12-\mathrm{x})} \mathrm{Al}_{\mathrm{x}} \mathrm{O}_{22}$ Y-Type Hexaferrites by the Sol-Gel Combustion Method, Integrated Ferroelectrics, 2020, 212, 25-30, https://doi.org/10.1080/10584587.2019.1674985

23. Iqbal, M.J.; Farooq, S. Enhancement of electrical resistivity of Sr0.5Ba0.5Fe12O19 nanomaterials by doping with lanthanum and nickel. Materials Chemistry and Physics 2009, 118, 308-313, https://doi.org/10.1016/j.matchemphys.2009.07.056.

24. Lutteroti, L. MAUD tutorial-Instrumental broadening determination, 2006, 1-18 http://www.ing.unitn.it/ maud

25. Schneider, C.A.; Rasband, W.S.; Eliceiri, K.W. NIH Image to ImageJ: 25 years of image analysis. Nat Methods 2012, 9, 671-675, https://doi.org/10.1038/nmeth.2089.

26. Chawla, S.K.; Meena, S.S.; Kaur, P.; Mudsainiyan, R.K.; Yusuf, S.M. Effect of site preferences on structural and magnetic switching properties of CO-Zr doped strontium hexaferrite SrCoxZrxFe(12-2x)O19. Journal of Magnetism and Magnetic Materials 2015, 378, 84-91, http://dx.doi.org/10.1016/j.jmmm.2014.10.168.

27. Teh, G.B.; Wong, Y.C.; Tilley, R.D. Effect of annealing temperature on the structural, photoluminescence and magnetic properties of sol-gel derived Magnetoplumbite-type (M-type) hexagonal strontium ferrite. Journal of Magnetism and Magnetic Materials 2011, 323, 2318-2322, https://doi.org/10.1016/j.jmmm.2011.04.014.

28. Ashiq, M.N.; Iqbal, M.J.; Gul, I.H. Structural, magnetic and dielectric properties of $\mathrm{Zr}-\mathrm{Cd}$ substituted strontium hexaferrite (SrFe12O19) nanoparticles. Journal of Alloys and Compounds 2009, 487, 341-345, https://doi.org/10.1016/j.jallcom.2009.07.140.

29. Josyulu, O.S.; Sobhanadri, J. The far-infrared spectra of some mixed cobalt zinc and magnesium zinc ferrites. physica status solidi (a) 1981, 65, 479-483, https://doi.org/10.1002/pssa.2210650209.

30. Baykal, A.; Güngüneş, H.; Sözeri, H.; Amir, M.; Auwal, I.; Asiri, S.; Shirsath, S.E.; Demir Korkmaz, A. Magnetic properties and Mössbauer spectroscopy of $\mathrm{Cu}-\mathrm{Mn}$ substituted BaFe12O19 hexaferrites. Ceramics International 2017, 43, 15486-15492, https://doi.org/10.1016/j.ceramint.2017.08.096.

31. Waldron, R.D. Infrared Spectra of Ferrites. Physical Review 1955, 99, 1727-1735, https://doi.org/10.1103/PhysRev.99.1727.

32. Lechevallier, L.; Le Breton, J.M.; Wang, J.F.; Harris, I.R. Structural analysis of hydrothermally synthesized Sr1-xSmxFe12O19 hexagonal ferrites. Journal of Magnetism and Magnetic Materials 2004, 269, 192-196, https://doi.org/10.1016/S0304-8853(03)00591-2. 
33. Kagdi, A.R.; Solanki, N.P.; Carvalho, F.E.; Meena, S.S.; Bhatt, P.; Pullar, R.C.; Jotania, R.B. Influence of $\mathrm{Mg}$ substitution on structural, magnetic and dielectric properties of X-type bariumzinc hexaferrites Ba2Zn2xMgxFe28046. Journal of Alloys and Compounds 2018, 741, 377-391, https://doi.org/10.1016/j.jallcom.2018.01.092.

34. Gaffoor, A.; Naidu, K.C.B.; Ravinder, D.; Batoo, K.M.; Adil, S.F.; Khan, M. Synthesis of nano-NiXFe2O4 ( $\mathrm{X}=\mathrm{Mg} / \mathrm{Co}$ ) by citrate-gel method: structural, morphological and low-temperature magnetic properties. Applied Physics A 2019, 126, https://doi.org/10.1007/s00339-019-3225-1.

35. Boda, N.; Naidu, K.C.B.; Basha, D.B.; Ravinder, D. Structural and Magnetic Properties of CdCoFe2O4 Nanoparticles. Journal of Superconductivity and Novel Magnetism 2020, 33, 1039-1044, https://doi.org/10.1007/s10948-019-05242-1.

36. Kumar, D.R.; Lincoln, C.A.; Ravinder, D.; Ahmad, S.I. Structural, morphological, luminescence, magnetic, and electrical transport properties of zinc-doped MnFe2O4 nanomaterials. Applied Physics A 2020, 126, https://doi.org/10.1007/s00339-020-03894-8.

37. Cernea, M.; Florentina Negrea, R.; Veronica Ciuchi, I.; Baldisserri, C.; Trusca, R.; Galassi, C. Dielectric characterization of BaxSr1-xFe12O19 (x=0.05-0.35) ceramics. Ceramics International 2016, 42, 10501056, https://doi.org/10.1016/j.ceramint.2015.09.029.

38. Iwauchi, K. Dielectric Properties of Fine Particles of Fe3O4and Some Ferrites. Japanese Journal of Applied Physics 1971, 10, 1520-1528, https://doi.org/10.1143/JJAP.10.1520.

39. Iqbal, M.J.; Ashiq, M.N. Physical and electrical properties of $\mathrm{Zr}-\mathrm{Cu}$ substituted strontium hexaferrite nanoparticles synthesized by co-precipitation method. Chemical Engineering Journal 2008, 136, 383-389, https://doi.org/10.1016/j.cej.2007.05.046.

40. Ansari, M.M.N.; Khan, S.; Ahmad, N. Structural, electrical transport and magnetic properties of Nd3+ substituted $\mathrm{Mn}-\mathrm{Cu}$ nanoferrites. Journal of Alloys and Compounds 2020, 831, https://doi.org/10.1016/j.jallcom.2020.154778.

41. Noor, A.; Akhtar, M.N.; Khan, S.N.; Nazir, M.S.; Yousaf, M. Synthesis, morphological and electromagnetic evaluations of $\mathrm{Ca}$ doped $\mathrm{Mn}$ spinel nanoferrites for $\mathrm{GHz}$ regime applications. Ceramics International 2020, 46, 13961-13968, https://doi.org/10.1016/j.ceramint.2020.02.194. 